\title{
What to do? A Review of the Academic Time-Based Decision-Making Literature
}

\author{
Nicholas J. Rupar and David S. Strong \\ Queen's University \\ nicholas.rupar@queensu.ca,david.strong@queensu.ca
}

\begin{abstract}
Time-based activities at Universities are shifting toward a more transactional approach, yet there is little understanding of the time management capabilities of students in adapting to a more flexible structure. Although many studies report on efforts to address engineering students being stressed, surfacelearning oriented, and prone to missing class, few studies address how these relate to students' time management.

In an effort to explore how students value, prioritize, and spend their time, this paper proposes a new term, "Academic Time-Based Decision-Making" (ATBDM), which lies at the crossroads of time management, selfefficacy, and self-regulated learning.

Factors influencing ATBDM are currently mostly speculative, although class scheduling, social norms, and the internet and social media are frequent causal suggestions. It is also unknown as to how ATBDM is conducted across the breadth of students, which skills or "tools" are employed, and whether the process or influencing factors change over the course of time.

$A$ research study to explore why and how engineering students make academic decisions is proposed. By providing deeper insights into the factors influencing $A T B D M$, it may be possible to develop more effective support or intervention to assist students in making balanced and positive choices.
\end{abstract}

Keywords: Time Management, Decision Making, Self-Regulated Learning, Self-Efficacy, Interventions, Mental Well-being.

\section{Introduction}

"We believe that time deserves its own decisionmaking literature because it is a resource like no other. Unlike money, time is possessed in equal amounts by everyone but is still subject to theft ... and abuse... Unlike energy, time is not renewable, recoverable, or substitutable. Furthermore, the value of time is ambiguous. Everybody knows that a dollar is a dollar, but an hour can mean different things to different people."

- Aeon and Aguinis, 2018 [1]

Notions of spending and prioritizing time have begun to change in the new age of technology. Technology has merged the gap between work life and home life, resulting in workers perceiving less and less control over their time [2]. This change is reflected in universities, which are also switching from a collective notion of time to a transaction-based notion of time [3]. This is exemplified in part by online learning and chaotic class scheduling - online learning, for example, is known to pose distinctly different challenges in terms of time management [4]. Issues with lack of control over time have been studied directly in Australian engineering students, and indirectly in Canadian students [5][6].

In Canada, some engineering students are beginning to react to the new transactional time expectations in different ways. Kuley, Maw, and Fonstad found that "Students felt that there was barely enough time to do the assignments each week, and that the heavy workload was not conducive to better learning" [7]. Other engineering educators are finding that students are now becoming "more strategic learners, valuing grades over learning," which may be related to the transactional nature of the student's time [8]. Doré identified in 2016 that some fourth-year engineering students are skipping their studies because of both concern for their own well-being and a focus on short-term enjoyment [6]. One of Doré's students justified their absence by stating that "everything is accessible. Courses therefore are worth the information they offer" [6].

The feelings of lack of time and overburden of work seem to be true across the field of engineering education. Kuley et al. noted that students are "not asking for easier work, but rather to have enough time to better grasp the concepts" [7]. Studies have noted poor time management in engineering students, and have linked time management and self-regulated learning to personal traits, characteristics, and success. Other studies identify the rational for students' decision-making and timemanagement - a recent example from the United States noted that the reasons behind low homework completion rates can be categorized into different loci of control [9].

Ultimately, there is a gap in the rich understanding of the diversity of individual students' ways of deciding how to spend their time. A study of this phenomenonwhich is defined here as Academic Time-Based Decision-Making (ATBDM) - may lead to better understanding of the student, institutional, and other variables that could be used to improve the efficacy and efficiency of engineering undergraduate programmes.

This paper will provide an overview of theories relating to time management, self-efficacy, and self-

CEEA19; Paper 183

University of Ottawa; June 9-12, $2019 \quad-1$ of $8-$ 
regulated learning before discussing the current ATBDM situation in Canadian engineering schools. Speculated causes and attempted solutions to the issues associated with ATBDM are noted, and arising questions are presented thereafter. Finally, a preliminary direction of study for the lead author's master's thesis to answer some of these questions is discussed.

\section{What is Academic Time-Based Decision- Making?}

Academic Time-Based Decision-Making (ATBDM) is defined here as the act of how students value, prioritize, and decide to spend their time. This recognizes both that "Time Management" has a component of decisionmaking (commonly "planning" or "prioritizing"), and that decision-making also has a component of time (as a resource analogous to money) [1].

ATBDM goes beyond traditional time management to include topics in self-efficacy and self-regulated learning, recognizing that these have time-as-resource restrictions and time-as-motivator incentives. Behaviours such as procrastination as well as states of being such as burnout are examples of the wide range of interacting factors and actors in ATBDM.

This section will provide an overview of topics in perceptions of time, time management, self-efficacy, and self-regulated learning which are or may be related to students' ATBDM.

\subsection{Perceptions of Time}

Common perceptions of time are often described in terms of a resource (e.g. "time is money"); however it has been found that they are not equal: time is similar to, and yet very distinct from, money in terms of how it is viewed, valued, and spent from person to person [1][10]. Understanding the different perceptions and types of time is important to understand how decisions are made regarding how time is spent from a non-human centered approach.

2.1.1. Time Structures and Time Norms. Time structures are explicit, formalized constructions of time in the environment; for example, meeting start and end times, a standard workday, or dinner at $6 \mathrm{pm}$ [1]. Time norms are implicit constructions of time, such as when one is considered "late" or how long it should take to reply to someone via email. One may break a time norm by accident and request forgiveness, or on purpose to demonstrate power over others [1].

2.1.2. Types of Time. In 2013, an American study on the social definitions of time for university students found 6 categories of time based on how it is used [3]. Scheduled time is a structured time and can be formal or informal, and is generally imposed by constraints such as agenda, schedules, or calendars. Compressed time also makes use of structure, but it is the time perceived when under pressure to meet a deadline. Timeless time and endless time are non-structured times. Timeless time begins when one is no longer thinking about time, and can be resting "downtime" or "uptime," which may be analogous to the state of "flow." Endless time is when a project has no foreseeable end and is thus ongoing, such as during a long research project.

Wasted time is defined as the time that occurs while waiting for something to happen. The authors of that study defined this as negative, but it could be that wasted time is more of a mindset: the concept of "found time," which is not discussed in this article, is using this "wasted time" for productive means such as completing a small review task.

Finally, there is time as a goal. This encompasses lengthening or shortening time for its own sake. Examples include trying to do things more efficiently, such as completing homework as fast as possible ahead of meeting with friends.

\subsection{Time and Time Management}

Time management is usually seen as an individual issue. Understanding the individual and their interactions with time is important to understanding how and why different students make different decisions regarding time. It is also important to know if and how time management can be taught or assisted when trying to achieve better ATBDM outcomes.

2.2.1. Individual Traits and Behaviours. Three separate studies in the literature have found three different bases of time management factors and behaviours, highlighting the confusion that still exists in this area.

Francis-Smythe and Robertson in 1999 created the 5factor Time Personality Indicator, derived from 15 dimensions of "time personality" found in literature [11]. The five factors they identified were Leisure Time Awareness, Punctuality, Planning, Polychronicity (preference for doing one thing or multiple things at a time over different time scales), and Impatience.

Hellsten suggested seven essential time management behaviours in 2012: time analysis, planning, goal setting, prioritizing, scheduling, organizing, and establishing new and improved time habits. These make the three behaviour groups of setting goals, engaging in the mechanics of time management, and organization [12].

Aeon and Aguinis, in 2018, identified only three factors in time management: Time preferences (poly vs monochronic), Time boundary styles (segmenting vs integrating), and other (temporal orientation) [1].

2.2.2. Procrastination and Timely Approaches. Procrastination is usually assumed to be negatively delaying tasks; however, some believe that

CEEA19; Paper 183

University of Ottawa; June 9-12, $2019 \quad-2$ of $8-$ 
procrastination can be done both purposefully and accidentally. Others claim that intentional delaying a task is distinct from procrastination [13].

Strunk, Cho, Steele, and Bridges propose a theory of two-dimensional procrastination, supported by confirmatory factor analysis, of motivation and behaviour [13]. Motivation is either approach or avoid oriented (i.e. positive or negatively motivated), and behaviour is either procrastination or timely engagement (i.e. delay or no delay in action). They also found correlations between a student's preferred performance approach (mastery or performance) and their preferred procrastination style.

A 2013 study of German university students, found four profiles of procrastinators explaining $65 \%$ of the variance [14]. Confirmatory factor analysis identified four factors: lack of study- and self-management skills, preference for pressure and past successes, worries and fears, and discontent with studies. A latent profile analysis used combinations of these four factors to identify four student groups. Although two of the groups were not affected by procrastination, the other two were. Those who were affected were also found to be under psychological distress because of it: one group was primarily driven by fear and the other by discontentment. The study also noted that the worried and anxious students were those who had been studying the longest.

A study of psychology students in Australia found that conscientious students tend to have better time management scores and engagement scores [15]. It also found that students with higher engagement scores were more likely to be "quick" learners, whereas students with higher time management scores were likely to be "consistent" learners.

These three studies demonstrate that procrastination and timely decision-making are in fact complex constructs, not easily distinguished from traditional "time management" measures, and heavily inter-related with engagement, achievement goals and psychological stressors (i.e. mental wellness).

2.2.3. Tools and Strategies for Time Management. Time management tools generally serve the dual purposes of reminding and planning. Two classic examples are to-do lists and the calendar or schedule. There has been some interest in developing custom apps to develop and "gamify" time management skills for engineering-specific and the general student population in Spain and Ireland [16][17].

Anecdotally, several tools and strategies have been successful in different circumstances and for different students. Therefore, although there is some interest in apps and games, it may be the case that no single solution of method or strategy will work for every student.

2.2.4. Ability to train and learn. Time management is commonly thought to be teachable; however, traditional time management training does not seem to have much benefit, at least in the short-term. Aeon and Aguinis found self-reported time use efficiency scores increase after time management training, but found that objective scores (such as supervisor review and observational studies) have no statistical increase [1].

Oettingen et al. noted that time management training itself may not be targeting the right level of cognition to enact change [18]. They showed that imagining future successful time choices and contrasting that future with the present abilities increased the likelihood of the participants succeeding in their timebased goals. This study is one example of how integrating the topics of self-efficacy and self-regulated learning with time management, as done in ATBDM, is important.

\subsection{Self-Efficacy}

Self-efficacy is strongly associated with university student learning outcomes, and is closely related to selfregulation, meta-cognition, locus of control, motivation, and learning strategy. It can be improved and taught, and is higher in certain situations than in others [19]. Selfefficacy and related topics are essential for understanding different reasons behind the decision-making aspect of ATBDM. Understanding how students' decisions are influenced can help solve problems of motivation

The four pillars of self-efficacy as originally defined by Bandura and since confirmed by others are: social persuasion, performance accomplishments, vicarious experiences, and physiological reactions [19]. Social persuasion is the recommendations and advice of others, which is effective if delivered by educators, but more effective if delivered by peers. Performance accomplishments are similar tasks that have been previously completed, such as practice problems. Vicarious experiences are observations of others in similar contexts, including role models. In another study on engineering students, role models were found to be especially effective for women in engineering [20]. Physiological reactions, finally, are related to the negative responses of stress and burnout, but also positive responses such as in friendly competition [19].

Research studies throughout Western nations, including Canada, have found that the relation of achievement to self-efficacy in a university setting is closely related to 20 other variables including metacognition and self-regulation [19]. Aufflik et al. give 11 recommendations, and suggest focusing "particularly on value, self-regulation and metacognition, locus of control, intrinsic motivation, and learning strategy use" when studying and improving self-efficacy in students [19].

2.3.1. Agency. Agency is the notion that one has the power and capability to perform actions. It is created in social contexts in such a way that it actually affects

CEEA19; Paper 183

University of Ottawa; June 9-12, $2019 \quad-3$ of $8-$ 
neuron growth in the brain [21][22]. Agency in the ATBDM-related literature often refers to personal agency of students, although agency can also be attributed to organizations, positions, and even rituals [23].

Agency is related to the idea of locus of control-a method of understanding which events are within and out of one's control-in that agency shapes a person's perspective on what is in and out of their control [9][5]. Agency is also strongly related to culture: broader cultural change towards a focus on individuals (including with respect to time) has been associated with additional stress on students because they are expected to be more in control, but have less structure in which to define themselves [24][22].

2.3.2. Burnout and Engagement. Burnout is a result of continuous, arduous psychological pressure characterized by cynicism, exhaustion, and reduced self-efficacy, whereas engagement is characterized by vigor, dedication, and absorption [25]. The two are considered to be strongly negatively correlated with one another [25]. Hellsten identified that "inefficient time use, lack of control over time demands, and inadequate amounts of time appears to have a negative impact on individual's psychological resources," which may in the long-term lead to burnout [12].

A study of Australian professional healthcare students found that students who experience burnout in their last year of studies were more likely to have it recur in the workplace. School burnout was also more prevalent and had a larger effect than workplace burnout [26]. The authors of that study note that preventing student burnout may therefore have positive effects on reducing later workplace burnout. As the subjects for this study were students in a "professional practice" undergraduate program, it is possible that the same effects may be present in engineering students.

While engagement scores have been positively correlated with success via GPA and test-pass rates, burnout is not always correlated with failure [25][26].

\subsection{Self-Regulated Learning}

Self-regulated learning (SRL) is defined by Zimmerman as a 3-part cycle consisting of forethought, performance, and self-reflection. It is recommended as the most applicable variable related to self-efficacy in education [19]. SRL comprises or is related to metacognition, motivation, decision-making, and futuretime perspectives. SRL and related concepts are essential in understanding the decision-making process of ATBDM.

\subsubsection{Metacognition and Decision-Making} Metacognition is the regulation of thinking processes [27]. Although there are multiple frameworks, it is generally understood that knowledge of cognition CEEA19; Paper 183

University of Ottawa; June 9-12, 2019

$$
-4 \text { of } 8-
$$

(including knowledge of people, tasks, and strategies) and regulation of cognition (planning, monitoring, controlling, and evaluating) are the two components of metacognition [27].

A self-regulated model for decision making in engineering students consisting of three factors has been established through confirmatory factor analysis [28]. The factors are generation and evaluation of ideas, impulsiveness and lack of process, and reflection. The self-regulated decision-making process may also make use of Future Time Perspectives, which is the orientation of an individual as to how they perceive the future [29]. This is an important issue in ATBDM, as it may help students reach better decisions.

2.4.2. Motivation and Achievement. Motivation in education is often described by the Motivation Learning Strategies Questionnaire, which has been tested in an American engineering context [30]. The questionnaire measures motivation orientation, motivation belief, learning strategies cognition, and regulatory strategies.

The other side of motivation is related to achievement goals, including the approach/avoid dimension and the performance/mastery dimension [13]. Surface learning and deep learning are generally understood to be the results of performance versus mastery approach. The approaches are situationallydependent: coping modes of learning may be employed by students in time crunches or when under duress [31]. The decision to employ a coping mode may be affected by one's motivation and approach to achievement in the task involved, and is thus essential to ATBDM.

2.4.3. SRL and Blended Learning. Blended learning has been shown to be more effective than either online or face-to-face learning alone, but is also speculated to require more self-regulation [32]. In one Australian study, it was shown that poor self-regulation strategies were a direct predictor of lack of success in the course (by final grade), whereas good self-regulated strategies were mediated via online activity to correlate with success in the class [32].

\section{Engineering Students and ATBDM}

The engineering education literature contains many references to poor time-based decisions and the effects thereof. Unfortunately, there are few studies that examine the root causes of this, although some researchers and professors do speculate as to the causes. The following section will summarize the state of ATBDM-related issues in an engineering context.

\subsection{An Overview of Engineering Students}

It is suggested that engineering students prioritize surface learning in their studies. In a review of the state 
of Canadian engineering education, it was noted by one professor's response that students seem to be prioritizing surface learning, looking for the "quick" answer to questions, rather than taking a deep approach [33]. Even when studying outside of class, engineering students might adopt a surface learning approach to complete assignments when under pressure [31]. A study from Guelph found that many students think that exam questions should be very similar to already completed problems, indicating a surface approach to learning and low self-efficacy in solving new problems [34].

Class attendance is another issue. One professor, in a reflection on 5 years of teaching three upper-year courses, noticed that attendance rates were quite low in his lectures and tutorials, and that students were focused on other work while in his labs [35]. In some cases, students are choosing not to go to class because they believe that the information is available online and that going to class is therefore a waste of time [6]. Even when they do attend class, engineering student engagement and learning approach is affected by how much they like the course [36].

Although students feel overwhelmed by workloads in engineering, they may actually be spending less time than expected on academic studies, as was found across Finland [37]. Other commitments, including family and work, have also been noted as reasons for not completing homework [9]. In some cases, students feel compelled to cheat to try and keep up in their courses due to a sense of overwhelming workload [38]. Ironically, a majority of students are able to find time for extracurriculars such as design teams, so some institutions have responded by creating courses that credit these types of activities [39].

3.1.1. Burnout and Stress. Across Canada, engineering students feel stressed, burnt out, and overwhelmed with their studies [40]. Most attributed this to the high workloads, although a belief of a hypercompetitive workforce culture may be overly pressuring students to avoid low grades [40]. Students are also contending with new issues, such as social media; social media interruptions while studying is correlated with lower GPA [41]. The expectation of being constantly available via technology may also be impacting the student's mental health [5].

3.1.2. Scheduling and Assignment Deadlines. There does not appear to be a study detailing the current state of homework deadlines and class scheduling among engineering students. Anecdotally, it is normal to have assignments due late into the night, and sometimes on weekends, because of online submissions. It is also not uncommon to expect to have a regular class anytime between 8:30 am and 9:30 pm. Mandatory labs and elective courses are often scheduled in the evenings, which can make it difficult to schedule extracurriculars.
Additional anecdotal evidence suggests that long blocks of classes (sometimes six hours or more) without a break is common, as is having several one-hour breaks between classes. Long blocks can be exhausting and inefficient for learning, and multiple short breaks can be difficult to use efficiently, as they are often reduced by travel time between buildings, and require more frequent engagement and disengagement with tasks. These scheduling issues may prove to be contributory factors to ATBDM.

\subsection{Academic-Based Interventions}

ATBDM issues have shown to manifest themselves in many ways. Institutions have created several responses to these, including detection of struggling students, posthoc interventions, concurrent interventions, additional credit courses, and changing courses.

In terms of detection, Sowinksi et al. of the University of Ottawa developed a screening test to find students on track for failure due to poor habits [42]. Preliminary tests showed that it was effective in identifying the students in need of aid.

Examples of post-hoc interventions include the GENE 101 course taught at the University of Waterloo and the Extended First-Year Program at Queen's University, which promote academic strategies and skills, and offer same year course repeat opportunities to students who struggle in their first fall semester [43][44]. These courses are considered successful, but may be missing students who only identify the need for assistance after their first year.

Concurrent interventions work during the year while students are struggling. Cunningham et al. in America have attempted to create a resource to increase student metacognition [27]. In Canada, Aleong and Strong ran a workshop mini-series to help student's selfregulation in lifelong learning. The results were mixed: the students found it very useful, but only four completed it [45]. More recently, Evans at University of Toronto implemented metacognitive reflections in a second-year environmental engineering course to change student's learning outlook with encouraging results [46]. Maleki, Picolo, and Verrett at UBC tested a 50-minute workshop on self-regulated learning with some positive selfreported results [47].

Changing incentives may also help. In the United States, an effective intervention for homework completion was to give a nominal bonus for submitting the work 24 hours in advance [9]. This study had the added result of motivating students who did not typically complete homework on time.

Other approaches include courses that run parallel with extracurricular design projects for credit, or those that teach leadership [48][39]. These courses attempt to leverage the learning environments of students outside the classroom to confer sound knowledge and practices.

CEEA19; Paper 183

University of Ottawa; June 9-12, $2019 \quad-5$ of $8-$ 
There are mixed results when it comes to evaluations such as report-writing, as students don't always appreciate the "extra" work [39].

Modifying the structure and timing of the course may also offer benefits. Akgunduz and Zeng are attempting to place more difficult courses during their student's peak cognitive times according to their circadian rhythms [49]. Other examples include courses that replace some or all lectures with online video to reduce class hours and create flexible timing for student engagement.

\subsection{Speculations on Causes of Poor ATBDM.}

There is still a poor understanding of certain aspects of ATBDM such as the decision to attend class, the impact and use of deadlines and break time, and the impact of social media and the internet. Doré's senior students avoided classes because they wanted to spend more time doing social activities before graduationwhich may actually be a false dichotomy [6]. Manjikian speculates on many causes for absences in his lectures, including morning lecture times, other more difficult classes which students are prioritizing, and the cold winter weather [35]. Furthermore, it may be the case that students who procrastinate are doing assignments late at night before a midnight deadline, and then not having time to get a proper night's sleep before morning classes.

The way in which students spend their breaks is also not well-known. It could be the case that poor management of break time leads to a higher perceived workload than actual workload. It may also be possible that having more breaks between classes is causing students to suffer decision fatigue and make poor choices, especially with the rise of distractions from the internet.

\section{Questions That Arise}

There are several unknown factors that can be investigated with respect to ATBDM, including how decisions change over time, what factors underlie it, and what are the outcomes. Do student's priorities change over the course of a week or throughout the semester? How often are decisions changed or revisited and why? What happens to student's ATBDM when an irregularity, such as unexpected personal matter occurs? What factors are considered by the student when making decisions? How do social norms affect how students spend their time? What institutional factors affect ATBDM, and can they be controlled? Do students regret the academic decisions they have made, and if so do they learn from them? What opportunity costs in terms of learning experience, psychological stress, and monetary impact result from student's decisions?

Answers to these questions may lead to focused interventions, such as choosing coping strategies, tools and other support initiatives that students might

CEEA19; Paper 183

University of Ottawa; June 9-12, 2019

$$
-6 \text { of } 8-
$$

effectively use. These interventions could help reduce strain on students and institutions by reducing burnout and promoting more efficient learning.

\subsection{Proposed Direction of Study}

The authors intend to explore the area of personal and institutional factors that affect ATBDM. A concurrent mixed-methods study will give both insight into wider trends and explanations of students' ATBDM choices. The main goals of the study will be to evaluate how ATBDM changes over the course of a semester, and examine what, if any, coping strategies students employ at different times during the semester.

A single-institution study is proposed as a next phase, incorporating study participants from a wide range of years, disciplines, extracurricular involvement, engineering experience, post-secondary motivation, and familiarity with time-management and SRL training.

\section{Conclusions}

Academic-related scheduling at many universities is slowly evolving away from inflexible classes and deadlines toward a system that accommodates a more transactional nature of student learning. To inform and optimize this evolution, there is a need to understand student time management and decision making, separate from other forms of decision making. This paper proposes the use of the term Academic Time-Based Decision-Making to explain how students value, prioritize, and decide to spend their time.

ATBDM is closely connected to self-efficacy, selfregulated learning, and related variables via influencing factors such as procrastination, metacognition, and burnout. As such, ATBDM relates directly to attendance, homework rates, and motivation, and indirectly to student stress and behaviours, and institutional settings.

Some solutions to ATBDM-related solutions are already in place to detect and mitigate student stressors and engagement, but a deeper understanding into the causes of ATBDM might lead to more efficient interventions.

Questions that are still unanswered include how does ATBDM change over time? What are the underlying factors? How do these factors interact? A research study examining the personal and institutional factors influencing ATBDM is proposed to respond to these and other related questions.

\section{Acknowledgements}

The authors would like to thank the Faculty of Engineering and Applied Science at Queen's University for their financial support in this research.

\section{References}


[1] B. Aeon and H. Aguinis, "It's About Time: New Perspectives and Insights on Time Management," Acad. Manag. Perspect., vol. 31, no. 4, pp. 309330, Nov. 2017.

[2] M. Huijer, "Book Review: Pressed for time: The acceleration of life in digital capitalism by Judy Wajcman," Time Soc., p. 0961463X1775260, Jan. 2018.

[3] T. F. Liao, J. Beckman, E. Marzolph, C. Riederer, J. Sayler, and L. Schmelkin, "The social definition of time for university students," Time Soc., vol. 22, no. 1, pp. 119-151, Mar. 2013.

[4] S. L. Miertschin, C. E. Goodson, and B. L. Stewart, "Managing Time in Online Courses: Student Perceptions," presented at the 2012 ASEE Annual Conference \& Exposition, 2012, pp. 25.911.125.911.14.

[5] M. Bunn, A. Bennett, and P. J. Burke, "In the anytime: Flexible time structures, student experience and temporal equity in higher education," Time Soc., p. 0961463X1878764, Jul. 2018.

[6] S. Doré, "What Seniors Have to Say About Their Engagement," Proc. Can. Eng. Educ. Assoc. CEEA, Jan. 2017.

[7] E. Kuley, S. Maw, and T. Fonstad, "Understanding Barriers to Student Success: What Students Have to Say," Proc. Can. Eng. Educ. Assoc. CEEA, Jan. 2017.

[8] N. Nelson and R. Brennan, "A Snapshot of Engineering Education in Canada," in Proc. 2018 Canadian Engineering Education Association (CEEA-ACEG18) Conf., 2018.

[9] W. Li, R. M. Bennett, T. Olsen, and R. McCord, "Engage Engineering Students In Homework: Attribution Of Low Completion And Suggestions For Interventions," Am. J. Eng. Educ. AJEE, vol. 9, no. 1, pp. 23-38, Jul. 2018.

[10] M. Wittmann and M. P. Paulus, "Decision making, impulsivity and time perception," Trends Cogn. Sci., vol. 12, no. 1, pp. 7-12, Jan. 2008.

[11] J. Francis-Smythe and I. Robertson, "Time-Related Individual Differences," Time Soc., vol. 8, no. 2-3, pp. 273-292, Sep. 1999.

[12] L.-A. M. Hellsten, "What Do We Know About Time Management? A Review of the Literature and a Psychometric Critique of Instruments Assessing Time Management," Time Manag., Mar. 2012.

[13] K. K. Strunk, Y. Cho, M. R. Steele, and S. L. Bridges, "Development and validation of a $2 \times 2$ model of time-related academic behavior: Procrastination and timely engagement," Learn. Individ. Differ., vol. 25, pp. 35-44, Jun. 2013.

[14] C. Grunschel, J. Patrzek, and S. Fries, "Exploring different types of academic delayers: A latent

CEEA19; Paper 183

University of Ottawa; June 9-12, 2019

$$
-7 \text { of } 8-
$$

profile analysis," Learn. Individ. Differ., vol. 23, pp. 225-233, Feb. 2013.

[15] H. E. Douglas, M. Bore, and D. Munro, "Coping with University Education: The relationships of Time Management Behaviour and Work Engagement with the Five Factor Model Aspects," Learn. Individ. Differ., vol. 45, pp. 268-274, Jan. 2016.

[16] Cassells, Tracy and 'O Broin, Daire, "Investigating the use of Game Elements in Motivating TimeManagement for Students," presented at the European Conference on Games Based Learning, 2017, pp. 784-792.

[17] R. Hernandez-Linares, H. Sánchez, J. E. Agudo, and M. Rico, "Chronos: A tool to develop the time management competence among engineering students," Comput. Appl. Eng. Educ., vol. 25, no. 1, pp. 79-89, Jan. 2017.

[18] G. Oettingen, H. B. Kappes, K. B. Guttenberg, and P. M. Gollwitzer, "Self-regulation of time management: Mental contrasting with implementation intentions," Eur. J. Soc. Psychol., vol. 45, no. 2, pp. 218-229, Mar. 2015.

[19] K. Bartimote-Aufflick, A. Bridgeman, R. Walker, M. Sharma, and L. Smith, "The study, evaluation, and improvement of university student selfefficacy," Stud. High. Educ., vol. 41, no. 11, pp. 1918-1942, Nov. 2016.

[20] E. L. Usher, N. A. Mamaril, C. Li, D. R. Economy, and M. S. Kennedy, "Sources of Self-Efficacy in Undergraduate Engineering," presented at the 2015 ASEE Annual Conference \& Exposition, 2015, pp. 26.1386.1-26.1386.18.

[21] A. Bandura, "Social Cognitive Theory: An Agentic Perspective," Annu Rev Psychol, vol. 52, p. 28, 2000.

[22] M. L. Wehmeyer et al., "Personal SelfDetermination and Moderating Variables that Impact Efforts to Promote Self-Determination," Exceptionality, vol. 19, no. 1, pp. 19-30, Jan. 2011.

[23] M. A. Koschmann and J. McDonald, "Organizational Rituals, Communication, and the Question of Agency," Manag. Commun. Q., vol. 29, no. 2, pp. 229-256, May 2015.

[24] S. Clegg, "Theorising the mundane: The significance of agency," Int. Stud. Sociol. Educ., vol. 15, no. 2, pp. 149-164, Jul. 2005.

[25] W. B. Schaufeli, I. M. Martínez, A. M. Pinto, M. Salanova, and A. B. Bakker, "Burnout and Engagement in University Students: A CrossNational Study," J. Cross-Cult. Psychol., vol. 33, no. 5, pp. 464-481, Sep. 2002.

[26] T. G. Robins, R. M. Roberts, and A. Sarris, "The role of student burnout in predicting future burnout: exploring the transition from university to 
the workplace," High. Educ. Res. Dev., vol. 37, no. 1, pp. 115-130, Jan. 2018.

[27] P. Cunningham, H. M. Matusovich, D. A. N. Hunter, and R. E. McCord, "Teaching metacognition: Helping engineering students take ownership of their own learning," in 2015 IEEE Frontiers in Education Conference (FIE), 2015, pp. 1-5.

[28] M. K. Orr, K. M. Ehlert, M. Rucks, and M. Desselles, "Toward the Development of a Revised Decision-Making Competency Instrument," presented at the 2018 ASEE Annual Conference \& Exposition, 2018.

[29] J. Chasmar and K. M. Ehlert, "Cluster Analysis Methods and Future Time Perspective Groups of Second-Year Engineering Students in a MajorRequired Course," presented at the 2018 ASEE Annual Conference \& Exposition, 2018.

[30] O. Adesope, N. Hunsu, B. J. V. Wie, B. Austin, R. F. Richards, and P. Dutta, "Work in Progress: Assessing Engineering Students' Motivation and Learning Strategies - A Psychometric Analysis of the Motivated Strategies for Learning Questionnaire," presented at the 2017 ASEE Annual Conference \& Exposition, 2017.

[31] R. McCord and H. M. Matusovich, "Study Context Matters: A Case Study on How Time Crunches Lead to Coping Modes of Learning," presented at the 2017 ASEE Annual Conference \& Exposition, 2017.

[32] A. Pardo, F. Han, and R. A. Ellis, "Exploring the relation between self-regulation, online activities, and academic performance: a case study," in Proceedings of the Sixth International Conference on Learning Analytics \& Knowledge - LAK '16, Edinburgh, United Kingdom, 2016, pp. 422-429.

[33] R. Brennan, "A Systematic Review of Canadian Engineering Education Research 2004-2017," Proc. Can. Eng. Educ. Assoc. CEEA, Dec. 2018.

[34] R. Clemmer, K. Gordon, and J. Vale, "Will That Be on the Exam? - Engineering Student Perceptions of Assessments, Memorization, and Approaches to Learning," Proc 2018 Can. Eng. Educ. Assoc. CEEA-ACEG18 Conf, 2018.

[35] N. Manjikian, "Reflections on Five Years of Coherent Teaching Accross Three Courses on Digital Logic and Computer Systems," Proc 2017 Can. Eng. Educ. Assoc. CEEA17 Conf, 2017.

[36] L. Nadelson, K. K. Hardy, and D. Yang, "I Like Therefore I Learn! Engineering Student Motivation to Learn in Their Least and Most Favorite Courses," presented at the 2015 ASEE Annual Conference \& Exposition, 2015, pp. 26.870.126.870.12.

[37] S. Kolari, C. Savander-Ranne, and E.-L. Viskari, "Do our engineering students spend enough time

CEEA19; Paper 183

University of Ottawa; June 9-12, 2019 -8 of $8-$ studying?," Eur. J. Eng. Educ., vol. 31, no. 5, pp. 499-508, Oct. 2006.

[38] D. M. Smith and S. Maw, "Supplementary Results of the CAIS-1 Survey on Cheating in Undergraduate Engineering Programs in Saskatchewan," p. 7, 2017.

[39] P. Dumond, "A Course Based Approach to Recognizing Student Efforst in Engineering Design Competitions," p. 7, 2017.

[40] A. D'Entremont, "Being a C-student is the new normal: a literature review on grades, self-worth, and mental wellbeing," Proc. Can. Eng. Educ. Assoc. CEEA, Dec. 2018.

[41] L. D. Rosen, L. Mark Carrier, and N. A. Cheever, "Facebook and texting made me do it: Mediainduced task-switching while studying," Comput. Hum. Behav., vol. 29, no. 3, pp. 948-958, May 2013.

[42] A. Sowinski, M. Turcotte, G. Arbez, and D. Taylor, "One-Minute Quizzes to Identify Potential Students At Risk in Engineering Courses," in Proc. 2017 Canadian Engineering Education Association (CEEA17) Conf., 2017, p. 4.

[43] W. S. Owen, M. Barichello, and A. Prier, "The Development of Gene 101 - A 'Strategies and Skills for Academic Success' Course for First Year Engineering Students at Waterloo,” p. 7, 2018.

[44] Queen's Faculty of Engineering and Applied Science, "Extended Program." [Online]. Available:

https://my.engineering.queensu.ca/CurrentStudents/First-Year-

Studies/Section900/index.html. [Accessed: 04Mar-2019].

[45] R. J. Aleong and D. S. Strong, "The Development of Life-Long Learning Competencies: Positioning Students for Self-Regulation," Proc. Can. Eng. Educ. Assoc. CEEA, Aug. 2015.

[46] G. J. Evans, "A Windmills of Your Mind: Metacognition and Lifelong Learning," in Proc. 2018 Canadian Engineering Education Association (CEEA-ACEG18) Conf., 2018.

[47] A. Maleki, C. Picolo, and J. Verrett, "Effect of a Mini Lesson on Self-Regulated Learning on Students' Learning," in Proc. 2018 Canadian Engineering Education Association (CEEA18) Conf., 2018.

[48] J. Daniow and M. Klassen, "Supporting Engineering Student Leaders to Influence Organizational Culture Through a Co-Curricular Leadership Program," p. 4, 2017.

[49] A. Akgunduz and Y. Zeng, "Innovative Course Scheduling and Curriculum Design," Proc. Can. Eng. Educ. Assoc. CEEA, Jan. 2017. 